\title{
A Method for Determining Wear Resistance and Wear Depth of Thin-Layer Functional Coatings
}

\author{
M.A. Markov ${ }^{1}$, Yu.A. Fadin ${ }^{2}$, I.N. Kravchenko ${ }^{3}$, \\ A.L. Galinovsky ${ }^{4}$, A.N. Belyakov ${ }^{2}$, A.D. Bykova ${ }^{2}$ \\ ${ }^{1}$ St. Petersburg State Technological Institute (Technical University), 26 Moskovsky pr., St. Petersburg, 190013, Russia; \\ 2 Institute for Problems in Mechanical Engineering RAS, V.O., 61 Bolshoj pr., St. Petersburg, 199178, Russia; \\ ${ }^{3}$ Russian Timiryazev State Agrarian University, 49 Timiryazevskaya, Moscow, 127550, Russia; \\ ${ }^{4}$ Bauman Moscow State Technical University, building 1, 5, Baumanskaya 2-ya, Moscow, 105005, Russia \\ * Corresponding author. Tel.: +7 49997601 70. E-mail: kravchenko-in71@yandex.ru
}

\begin{abstract}
The surface of metallic materials in friction pairs is protected from contact interaction by applying functional coatings. The minimum loads set in standard friction machines can be critical and instantly abrade the modified surface. Consequently, new promising approaches are needed in the development of coating diagnostics. This paper presents the approbation of a new promising method for evaluating thin-layer coatings based on the acoustic emission method using a reference sample.
\end{abstract}

\section{Keywords}

Surface; wear; acoustic emission; Fourier spectrum; relative wear resistance; thin coating.

(C) M.A. Markov, Yu.A. Fadin, I.N. Kravchenko, A.L. Galinovsky, A.N. Belyakov, A.D. Bykova, 2020

\section{Introduction}

Currently, the surface of metallic materials in friction pairs is protected from contact interaction by applying functional coatings. If the coatings are thin, then the urgent problem is the development of new methods for comparative evaluation of their wear resistance. In most cases, parts with experimental coatings have a complex geometry; therefore, diagnostic devices must have non-standard parameters. Wear-resistant ceramic coatings based on refractory compounds (borides, carbides, metal silicides) are most widely used in industry [1-10].

It should be noted that the minimum loads specified in standard friction machines can be critical and instantly abrade thin-layer coatings. Consequently, new promising approaches are necessary for the development of this direction.

Quantification of wear caused by continuous friction is an interesting scientific and practical problem. Scientifically, data on current wear can provide detailed information on the physical mechanisms of wear and on changes in coating properties over time. In practical terms, the methodology for obtaining this data can be used for monitoring critical machine components, since their failures occur for reasons related to the state of materials. To organize feedback in such systems, signals from sensors which characterize the parameters of the system condition are used.

Characteristics of acoustic radiation, which can be quite clearly identified with the help of modern electronic equipment, provide the possibility of widespread use of acoustic emission (AE) for the diagnosis of friction and wear [11].

The aim of the study is to develop and test a new promising method for evaluating thin-layer coatings based on the application of acoustic emission using a reference sample.

\section{Methods}

In the study, thin-layer ceramic titanium nitride coatings were applied by magnetron sputtering. The method is based on the evaporation of the metal material of the cathode in the cathode-anode assembly 


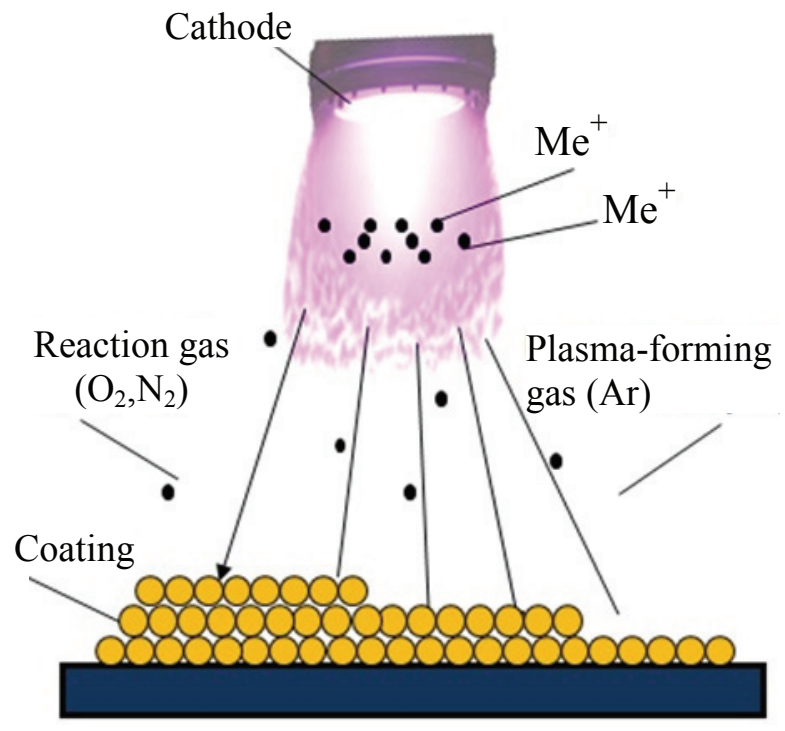

Fig. 1. The process of forming a coating with magnetron sputtering

of a vacuum installation and its subsequent deposition on a metal substrate. Depending on the composition of the plasma-forming and reaction gases in the working chamber, functional coatings can be obtained on the substrate from both pure metals and refractory nonmetallic compounds based on carbides, nitrides and metal oxides. A brief diagram of the process is shown in Fig. 1.

The deposition of titanium nitride coatings was carried out on a "Magna TM 5" magnetron sputtering installation in a nitrogen atmosphere. The coating thickness reached $20 \mu \mathrm{m}$.

\section{Results and discussion}

\section{Friction acoustic emission}

During the friction of solids, the emergence of three types of acoustic vibrations was found: selfexcited vibrations resulting from changes in the statistical, dynamic or kinematic conditions of mates; emission oscillations (AE) - stress waves caused by plastic deformation, structural phase rearrangement and destruction of the friction surface; surface waves.

It was also found that there is a feedback between friction and vibrations, i.e. friction generates vibrations, which in turn affect friction. Research in triboacoustics is therefore developing in two main directions: the establishment of the mechanism and regularities of the occurrence of various types of frictional acoustic vibrations and the assessment on their basis of the parameters of friction; analysis of the possibilities of changing the frictional interaction by forced oscillation of the friction pair.
Recently, intensive research has been carried out to study the patterns and mechanisms of the occurrence of acoustic emission during friction. Since AE is a direct reaction of a friction surface to contact interaction, its use to create continuous methods for studying and monitoring the process of friction and wear of pairings is very promising.

A large number of experimental studies focus on the main regularities of the emergence and development of acoustic emission when the external parameters of friction change. At the same time, the sensitivity of the emission parameters to the properties of a discrete contact is noticed, which largely determine the nature of frictional processes, the degree of their influence on the frictional parameters of friction units.

In this paper, we used the acoustic emission registration system developed at the A.A. Blagonravov Institute of Mechanical Engineering of RAS. The proposed algorithm made it possible to register experimental data in two ways: one is quite common it employs the use of a filtration unit, the second one is fundamentally new -the data from the sensor is entered into the analog-to-digital converter and a personal computer, bypassing the filtration stage (Fig. 2).

The hardware complex for recording $\mathrm{AE}$ corresponding to the "new" diagram includes: P 113 contact piezoelectric transducers made of TsTS-19 piezoelectric ceramics, designed for operation in the $0.2-1 \mathrm{MHz}$ range, an amplifier path from the AF-15 device, a 6023E multifunctional board, manufactured by National Instruments (USA), providing conversion of analog measuring signals into digital and personal computers. The hardware complex allows recording the time of occurrence of an AE event, its maximum amplitude and duration (number of vibrations) $[11,12]$.

\section{Development of a method to calculate the wear resistance of thin-layer coatings}

The study is based on the experimental data previously obtained by the authors, as described in [13]. In particular, it is known that the AE method can calculate the wear of a small amount of a substance, which is not determined on an analytical balance. To achieve this, it is necessary to implement the process of friction of materials. The result of the interaction is the accumulation of stresses and the destruction of the contacting surfaces. The destruction process is accompanied by the formation of microcracks. As the crack grows, the material is detached and carried away from the contact zone. Crack formation is accompanied by the release of acoustic energy. Thus, the sought-for connection between the mass of the worn-out substance and the actual energy of acoustic signals is realized. 


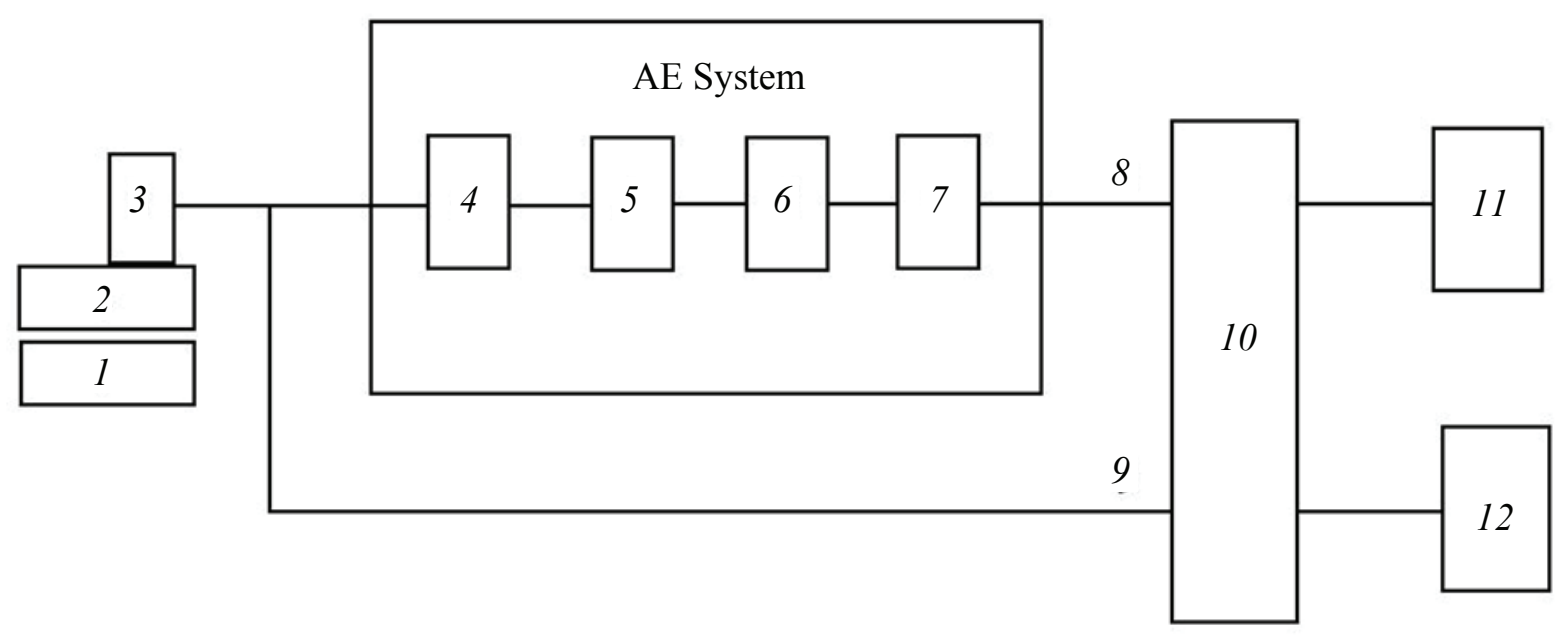

Fig. 2. Installation diagram for acoustic emission registration:

1 - movable sample; 2 - stationary sample; 3 - piezoelectric transducer; 4 - preamplifier; 5 - main amplifier; 6 - filters; 7 processing unit; 8 - the first channel of the oscilloscope; 9 - the second channel of the oscilloscope; 10 - 3107 "AKTAKOM" oscilloscope; 11 - computer-1; 12 - computer-2

The next step is to determine the wear rate based on the ratio of wear to the friction path. Within the framework of this study, the friction path along the coating surface was organized at a distance of several millimeters. In this case, the friction track should be flat and have precise dimensions. A needle-type indenter made of hard tool steel was used as a counterbody. After the interaction of the indenter with the coating, the friction track under study should have a depth less than the thickness of the coating. The next step is to try to determine the depth of the formed friction track and the intensity of wear.

To do this, it was necessary to draw a second, the so-called calibration friction track with an indenter for a thickness equal to the thickness of the coating (through scratch). During friction, an acoustic signal was connected and acoustic emission was recorded. Practical research of the authors shows that the processes of wear of materials during short-term interaction are accompanied by frequency signals in the range of $1-3 \mathrm{kHz}$.

We consider the Fourier spectrum of the recorded acoustic emission signal in order to select the useful frequency range (Fig. 3).

Based on the analysis [14], it is possible to calculate the mass wear $\Delta m$ by the formula:

$$
\Delta m_{i}=\alpha \sum_{f_{p}}^{f_{q}} S_{i}^{2}(f),
$$

where $\alpha$ is proportionality factor; $S_{i}$ is spectral components of an acoustic signal; $f_{p}, f_{q}$ are initial and final frequency range under consideration.

From the presented expression, one can determine the proportionality factor. This parameter is individual for a specific type of coating.

First, the wear of the material for the friction calibration track is determined. Here, the density of the

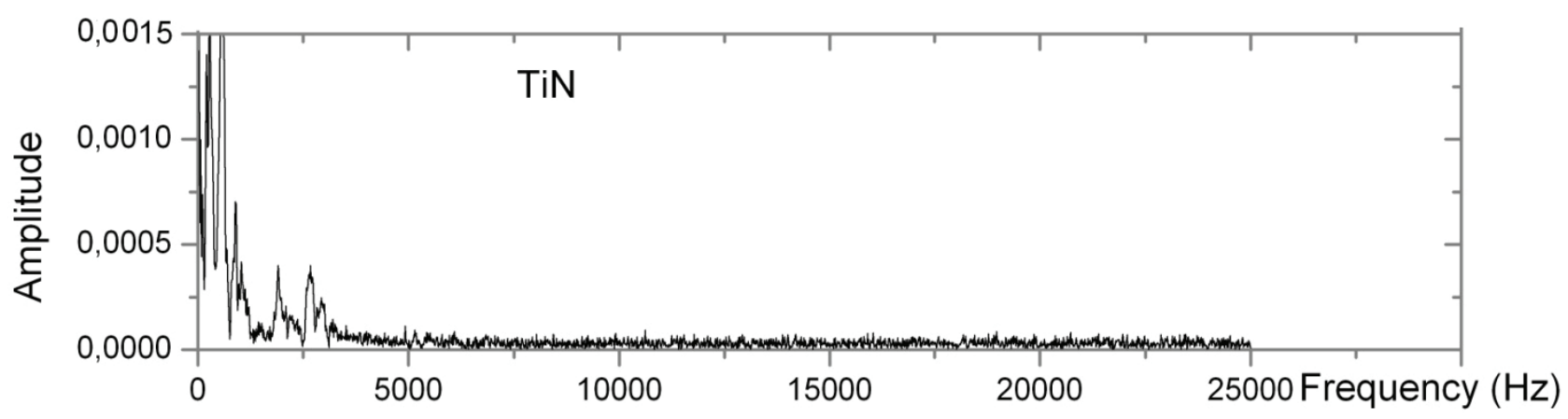

Fig. 3. Decomposition of a signal into a Fourier spectrum, friction track over a titanium nitride coating 
coating is known. Track depth is determined by standard gauge types as it is equal to the thickness of the coating. The length and average width of the scratch can be determined using optical or electron microscopy. The actual worn mass of the friction track is then determined. In accordance with the experimental conditions, the acoustic energy is calculated, after which the calibration factor $\alpha$ is found.

Having determined experimentally the calibration factor and acoustic energy for the investigated friction track, it is possible to calculate the volume of worn material and the average scratch depth. Finally, if the depth of the scratch and its length are known, it is possible to calculate the relative wear resistance of the coating.

The relative wear resistance of the titanium nitride coating was equal to $10^{10}$, which was quite plausible.

\section{Conclusion}

Based on the studies carried out, we proposed a promising method for assessing the wear resistance of thin-layer coatings, based on the analysis of acoustic emission signals using a calibration friction track.

\section{References}

1. Moskvitin G.V., Birger Ye.M., Polyakov A.N., Polyakova G.N. Naukoyemkiye tekhnologii naneseniya uprochnyayushchikh pokrytiy [Science-intensive technologies for applying hardening coatings]. Metalloobrabotka. 2015. 2.1(85), 44-49 (Rus)

2. Trefilova N.V. Analiz sovremennykh metodov naneseniya zashchitnykh pokrytiy [Analysis of modern methods of applying protective coatings. Modern high technologies ]. Sovremennyye naukoyemkiye tekhnologii. 2014, 10, 67-67 (Rus)

3. Suminov A.V., Epel'fel'd A.V. Lyudin V.B., Krit B.L., Borisov A.M. Mikrodugovoye oksidirovaniye (Teoriya, tekhnika, oborudovaniye) [Microarc oxidation (Theory, technique, equipment)]. Moscow: Ekomet, 2005, 368 p. (Rus)
4. Berlin Ye.B., Seydman L.A. Polucheniye tonkikh plenok reaktivnym magnetronnym napyleniyem [Obtaining thin films by reactive magnetron sputtering]. Moscow: Tekhnosfera, 2014, 260 p. (Rus)

5. Holmberg K., Matthews A. Coatihgs tribology Elsevier Science. 1994. 457 p.

6. Novak R., Polcar T. Tribological analysis of thin films by pin-on-disc: Evaluation of friction and wear measurement uncertainty. Tribology International. 2014, $74,154-163$

7. Perevislov S.N. Evaluation of the crack resistance of reactive sintered composite boron car-bide-based materials. Refractories and Industrial Ceramics. 2019, 60(3), 168-173.

8. Perevislov S.N. Shcherbak P.V., Tomkovich M.V. Phase composition and microstructure of reaction-bonded boron-carbide materials. Refractories and Industrial Ceramics. 2018, 59(2), 179-183.

9. Markov M. A. Previslov S.N., Krasikov A.V., Gerashchenkov D.A., Bykova A.D., Fedoseev M.L. Study of the Microarc Oxidation of Aluminum Modified with Silicon Carbide Particles. Russian Journal of Applied Chemistry. 2018, 91(4), 543-549.

10. Markov M.A. Krasikov A.V., Gerashchenkov D.A., Bykova A.D., Ordan'yan, S.S., Fedoseev M.L. Formation of Protective Ceramic-Metal Coatings on Steel Surfaces by Microarc Oxidation with Electro-Chemical Deposition of Nickel. Refractories and Industrial Ceramics. 2018, 58(6), 634-639.

11. Sviredenok A.I., Myshkin N.K., Kalmykova T.F., Kholodilov O.V. Akusticheskiye $i$ elektricheskiye metody $v$ tribotekhnike [Acoustic and electrical methods in tribotechnics]. Minsk: Nauka i Tekhnika, 1987. 280 p. (Rus)

12. Bezenkina, O.S. Kinetika iznashivaniya keramik: dis. ... kand. tekhn. nauk: 05.02.04 [Kinetics of ceramics wear: dis. ... Cand. Tech. Sci.: 05.02.04], St. Peterburg, 2013, 108 p. (Rus)

13. Fadin Yu.A. Primeneniye akusticheskoy emissii dlya otsenki massovogo iznosa [Application of acoustic emission to assess mass wear]. Treniye i iznos [Friction and wear], 2008, 29(1), 29-32. (Rus)

14. Knott J.F. Foundations of fracture mechanics. Moscow: Metallurgiya, 1978, $256 \mathrm{p}$. 